\title{
Study of Potential Phenolic Compounds from Stems of Dendrophthoe falcata (Loranthaceae) Plant as Antioxidant and Antimicrobial Agents
}

\section{SRI ATUN ${ }^{1 *}$, SRI HANDAYANI ${ }^{1}$, ANNA RAKHMAWATI ${ }^{2}$, NUR AINI PURNAMANINGSIH ${ }^{2}$, BIAN IHDA AN NAILA ${ }^{1}$ and ASTUTI LESTARI ${ }^{1}$}

\author{
1Department Chemistry Education, Faculty of Mathematics and Natural Science, \\ Universitas Negeri Yogyakarta, Indonesia. \\ 2Department of Biology Education, Faculty of Mathematics and Natural Science, \\ Universitas Negeri Yogyakarta, Indonesia. \\ ${ }^{*}$ Corresponding author E-mail: sriatun@uny.ac.id
}

http://dx.doi.org/10.13005/ojc/340515

(Received: April 04, 2018; Accepted: October 15, 2018)

\begin{abstract}
Dendrophthoe falcata is a hemiparasitic plant that has been used in traditional medicine. The study was conducted to identify the total phenolic and flavonoid compounds, to test antioxidant, and antimicrobial activity of ethanol extract stems of $D$. falcata parasite on Melia azedarach host tree. The dry powder stems of $D$. falcata was extracted with ethanol. The ethanol extract was subsequently partitioned successively using n-hexane, chloroform, and ethyl acetate. Each fraction was analyzed by a quantitative phenolic and flavonoid content with spectrophotometer method, and tested as antioxidant and antimicrobial activites. Antioxidant activity was performed by 2,2-diphenyl1-picrilhidrazil (DPPH) method, while antimicrobial assay used pathogenic bacteria by disk-diffusion method. The results concluded that the stem of $D$. falcata plant showed a high content of phenolic and flavonoid compounds, very high antioxidant and moderate antimicrobial activities. It was also found that stems of $D$. falcata contain potential phenolic compounds that can be used as natural antioxidants and the treatment of various infections caused by microbes.
\end{abstract}

Keyword: Dendrophthoe falcata, Antioxidant. Antimicrobial. Phenolic compound, Flavonoids.

\section{INTRODUCTION}

Loranthacea is a parasitic plant widely used in traditional Chinese medicine systems. One of this species is $L$. parasiticus which is known as Sang Ji Sheng (in Chinese), parasites (in Malay) and
baso-Kisei (in Japanese). The plants are commonly found as parasitic plants that attach to other plant stems. Parasites can be found in tropical and subtropical regions, but with different species diversity. ${ }^{1-4}$ L. parasiticus known as traditional medicine is widely used as a diuretic, high blood pressure,

This is an Open Access article licensed under a Creative Commons Attribution-Non Commercial-Share Alike 4.0 International License (https://creativecommons.org/licenses/by-nc-sa/4.0/), which permits unrestricted Non Commercial use, distribution and reproduction in any medium, provided the original work is properly cited. 
polio virus prevention ${ }^{5}$, antimicrobial and antiinflammatory ${ }^{6}$, and neuroprotective ${ }^{7}$, antioxidant ${ }^{8}$, and antidiabetic 9 .

Dendrophthoe falcata ( $D$. falcata) is one of the hemiparasitic plants commonly attached to host plants such as Mangifera indica (Anacardiaceae), Melia azedarach (Meliaceae) and Psidium guajava (Myrtaceae). The plant is widely distributed in tropical and sub-tropical regions. The whole plant of $D$. falcata is used in native treatment systems such as astringent, aphrodisiac, diuretics, and treat menstrual disorders, and antifertility agent ${ }^{10}$. It has been reported that methanol extract and water decoction of $D$. falcata leaves have anti-inflammatory effect on experimental animals and showed strong antioxidant activity by in-vitro ${ }^{11}$.

A study conducted by Chandrakasan ${ }^{2}$ comparing the ethanol extract stems of Loranthus longiflorus plants that are parasitic to the plant stems of Casuarina equisetifolia and Ficus religiosa by GC-MS showed different compounds and biological activity. A comparative study of the phytochemical and anti-microbial properties from leaf of Loranthus micranthus harvested from six host trees, showed marked variations in phytochemical constituents and anti-microbial activities ${ }^{12}$. The work reported by Chandrakasan ${ }^{13}$ showed the presence of cumarin compounds from leaf of $L$. longiflorus plant, whereas in fresh flowers Loranthus acaciae was reported to contain antimicrobial quercetin 3-O-glucoside. Research on chemical and biological studies of leaf extract of $D$. falcata showed the crude extracts and the fractions have potential biological activities as cytotoxic, antioxidant, and thrombolytic activities. The leaves of $D$. falcata have also been reported to contain compounds identified as lupeol, 3- $\beta$-acetoxy-12-ene11 -one and $\beta$-sitosterol ${ }^{14}$. In this work we report the potential of phenolic compounds from stems of $D$. falcata plant that hemiparasite on Melia azedarach host tree as antioxidant and antimicrobial agents.

\section{EXPERIMENTAL}

\section{Apparatus and reagents}

Evaporator Buchi Rotavapor R-114, spectronic 20, incubator, autoclave, LAF (Laminatory
Air Flow), coloni counter, forceps, micro pipettes, shaker, water bath, deep freezer, ruler (millimeter scale), petri plate, and analytical balance were used in this work. Ethanol, methanol, n-hexane, ethyl acetate, acetone, DPPH (2,2-diphenyl-1picrylhydrazyl), ascorbic acid, folin-ciocalteu, sodium carbonate, gallic acid, rutin, aluminum nitrate, potassium acetate, chloramphenicol, Mueller-Hinton agar (MHA, OXOID), Nutrient Broth (NB), Nutrient Agar (NA), paperdisk, DMSO (dimethyl sulfoxide), plastic wrap, aluminium foil, and aquadest were used in this work without particular treatment.

\section{Plant Materials}

The sample used in this study was a parasitic plant attached to the stem of the Melia azedarach host tree, collected in October 2017. The sample was then determined by Biology Laboratory as specimen (DF-01-2017) and scientifically known as Dendropthoe falcata (L.f.) Ettingsh, the local name of "benalu" or "kemadealan".

\section{Microorganism}

This study used four pathogenic bacterial isolates, three isolates of Escherichia coli ATCC 11229, Staphylococcus aureus ATCC25923, and Staphylococcus epidermidis FNCC 0048 were obtained from the Microbiology laboratory, while Streptococcus mutans was obtained from Dentistry laboratory. The microorganism were sub-cultured and stored in a semisolid medium (Mueller Hinton agar plates) at $4^{\circ} \mathrm{C}$ until needed.

\section{Preparation of samples}

The milled dried from stem of $D$. falcata (4 kg) was extracted using $95 \%$ ethanol as the solvent for $24 \mathrm{~h}$ and repeated 3 times. The extracts were then concentrated using a vacuum rotatory evaporator and yielded brown residue for about $72 \mathrm{~g}$. The ethanol extract of $D$. falcata $(60 \mathrm{~g})$ was successively partitioned using $n$-hexane, chloroform, and ethyl acetate. Each fraction was evaporated to dryness under vacuum resulting in a fraction of n-hexane (12 g), chloroform fraction (11.3 g), ethyl acetate fraction $(10.62 \mathrm{~g})$, and residual ethanol fraction $(22 \mathrm{~g})$. The procedure of sample preparation can be seen in Figure 1. 


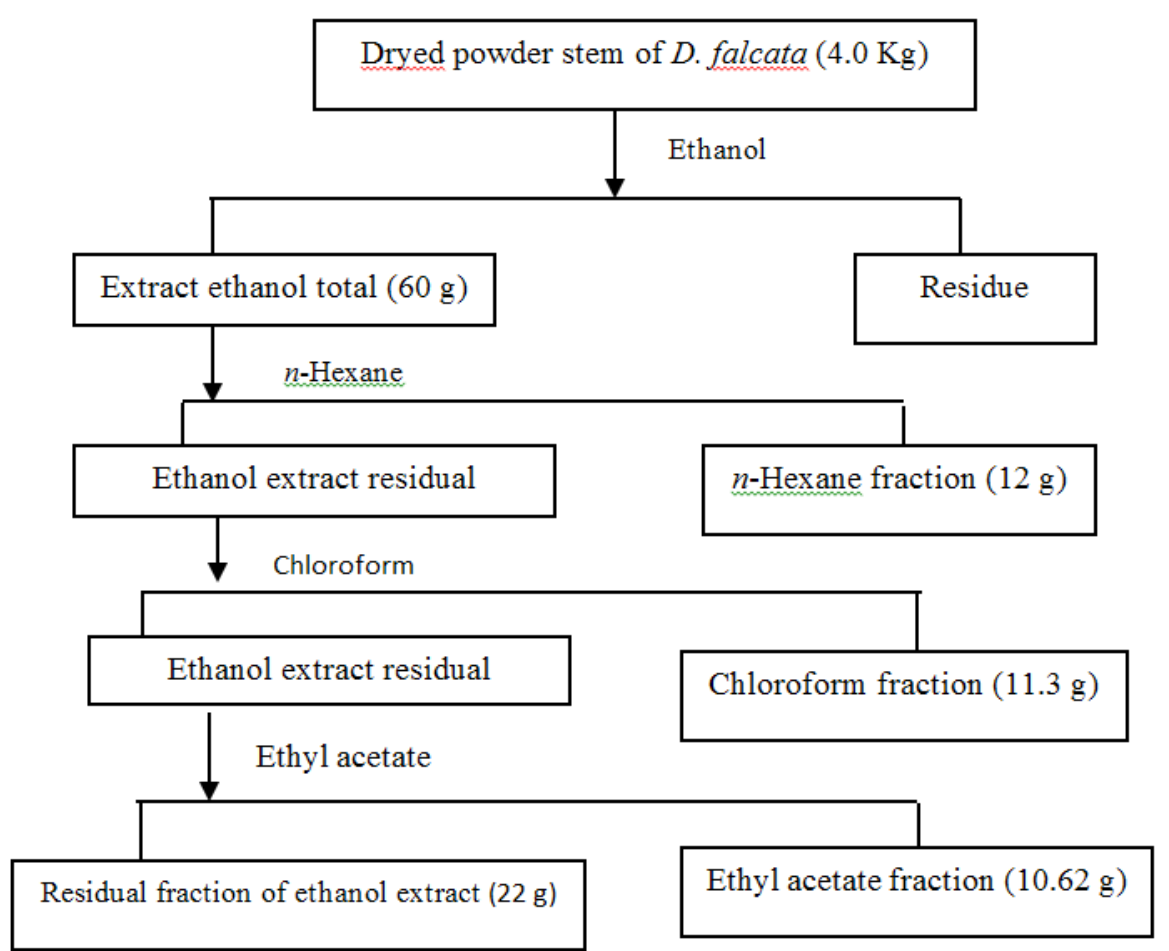

Fig. 1. The procedure of sample preparation

\section{Phytochemical screening}

The qualitative phytochemical screening was performed using reagent for terpenoid test, alkaloid test, phenolic test, and saponin test. Terpenoids test was performed using Salkowski reagent, alkaloid test was done with Wagner reagents, phenolic test was done with iron(III) chloride test, and foam test was for saponin ${ }^{15}$.

\section{Quantitative determination of total phenolic and flavonoid content}

The quantitative analysis of the total phenolic content of each extract and fractions were determined using the folin-ciocalteu reagent ${ }^{16}$. About $200 \mu \mathrm{L}$ of sample $(500 \mu \mathrm{g})$ was mixed with folin-ciocalteu reagent $(0.4 \mathrm{~mL})$, aquadest $(4 \mathrm{~mL})$ and sodium carbonate $(2 \mathrm{~mL}, 15 \% \mathrm{w} / \mathrm{v})$. The mixture was subsequently incubated at $50^{\circ} \mathrm{C}$ for $10 \mathrm{~min}$. and measured its absorbance at $760 \mathrm{~nm}$. The total phenolic content was calculated according to the standard curve specified for the gallic acid as a reference. Each measurement was performed three replicates. The total phenolic content is expressed as mg of Gallic Acid Equivalent (GAE) per g of plant extract.
The quantitative analysis of total flavonoid content was determined by spectrophotometric method. This method was adopted with a slight modification of Liu TC ${ }^{17}$. The samples of each extract were diluted with $80 \%$ ethanolic-aqueous solution $(0.9 \mathrm{~mL})$. A total of $0.5 \mathrm{~mL}$ of the sample was added to the reaction tube containing 0.1 $\mathrm{mL}$ aluminum nitrate $(10 \%), 0.1 \mathrm{~mL}$ of potassium acetate $(1 \mathrm{M})$ and $4.3 \mathrm{~mL}$ of ethanol (80\%). The mixture was incubated at room temperature for $40 \mathrm{~min}$. and its absorbance was determined at $415 \mathrm{~nm}$ with a UV spectrophotometer. Total flavonoid content was calculated using standard curves with rutin as references. The total flavonoid content is expressed as mg Rutin Equivalents (RE) per $g$ of plant extract.

\section{Determination of antioxidant activity test}

The antioxidant activity test of each sample was done by free radical scavenger method. This method used DPPH (2,2-diphenyl-1-picrylhydrazyl) as a source of free radicals ${ }^{18}$. A total of $5 \mathrm{~mL}$ of sample (in various concentrations between $100-3,125 \mu \mathrm{g} / \mathrm{mL}$ ) and positive control (ascorbic acid in various concentrations between $6.25-0.390 \mu \mathrm{g} / \mathrm{mL}$ ) were mixed with $5 \mathrm{~mL}$ of DPPH solution in methanol 
(0.12 $\mathrm{mM}$ ) and incubated at room temperature for 30 minutes. Absorbance was measured at $516 \mathrm{~nm}$ using spectronic 20 (Genesys). The absorption of DPPH from the sample was compared to the blank solution. Each sample was tested in three replications. Antioxidant activity was calculated as a reduced percentage of DPPH compared with control and inhibitory activity can be calculated to determine $\mathrm{IC}_{50}$.

\section{Determination of activity as an antimicrobial agent}

The antimicrobial activity test of the crude extract and each fraction were performed by agar diffusion method. This method was adopted with slight modifications of Bisnu ${ }^{19}$. In this work four bacteria i.e Escherichia coli ATCC-11229, Staphylococcus aureus ATCC-25923, Staphylococcus epidermidis FNCC-0048, and Streptococcus mutans were used. As a positive control chloramphenicol was applied, while DMSO (dimethyl sulfoxide) $10 \%$ was used as a solvent and also as a negative control.

The test bacteria of $100 \mu \mathrm{L}$ was inoculated onto the Muller Hinton agar plate, and flattened with drigalsky. The paperdisk was immersed in the

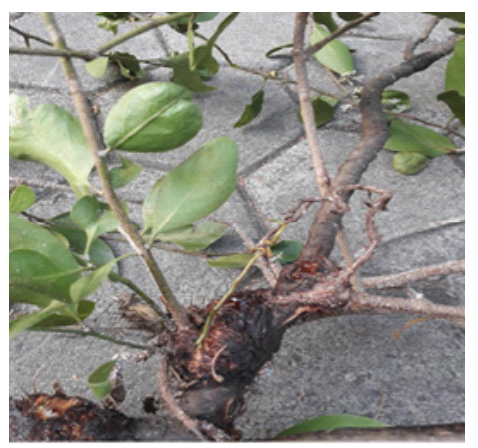

solution of each sample for five minutes and was dipped into the sample solution which was placed on top of the agar medium, and incubated at $37^{\circ} \mathrm{C}$ for $12 \mathrm{~h}$. After $12 \mathrm{~h}$ incubation, the zone of inhibition around the disks was measured in millimeter scale. A four serial dilution $(0.01 ; 0.1 ; 0.5$ and $1.0 \% \mathrm{w} / \mathrm{v})$ was carried out for each sample. The measurement was done in three repetitions.

\section{RESULTS AND DISCUSSION}

This study used stem bark of $D$. falcate that hemiparasite on Melia azedarach host tree (Fig. 2). After being dried and mashed the stem bark was extracted by maceration using $95 \%$ of ethanol solvent. Total concentrated ethanol extract obtained was about $72 \mathrm{~g}$. A portion of the extract (60 g) was partitioned using n-hexane, chloroform, and then ethyl acetate solvents. Each subsequent fraction was evaporated to dryness under vacuum. Each of the extracts and fractions were identified to phytochemical test and its activity as antioxidant and antimicrobial. The results of qualitative phytochemical test including terpenoid, alkaloid, phenolic, and saponin are listed in Table 1.

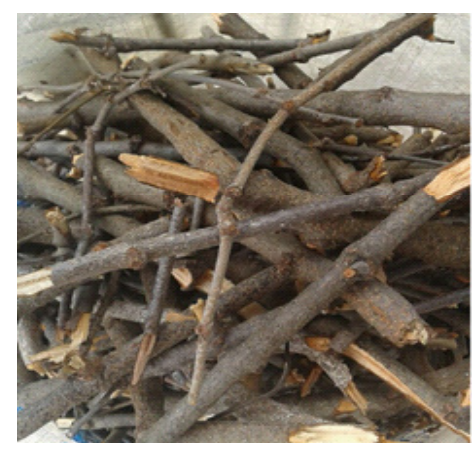

Fig. 2. Stem of $D$. falcata

Table 1: Qualitative phytochemical screening of the extracts and fractions from stem of $D$. falcata

\begin{tabular}{lccccc}
\hline $\begin{array}{l}\text { Qualitative phytochemical } \\
\text { screening }\end{array}$ & $\begin{array}{c}\text { Extract } \\
\text { ethanol total }\end{array}$ & $\begin{array}{c}\text { n-hexane } \\
\text { fraction }\end{array}$ & $\begin{array}{c}\text { Chloroform } \\
\text { fraction }\end{array}$ & $\begin{array}{c}\text { Ethyl acetate } \\
\text { fraction }\end{array}$ & $\begin{array}{c}\text { Residual fraction } \\
\text { of ethanol extract }\end{array}$ \\
\hline Terpenoid (Salkowski Test) & +++ & +++ & ++ & - & - \\
Alkaloid (Wagner Test) & + & - & + & - & - \\
Phenolic (FeCl test) & +++ & - & ++ & +++ & + \\
Saponin (Foam test) & +++ & - & - & + & +++ \\
\hline
\end{tabular}

Note: - = absent, + = present, ++ = present a lot; +++ = present very large number

Quantitative analysis of total phenolic content was performed by spectrophotometer following the Folin-Ciocalteu method ${ }^{17}$. The absorbance of each sample was recorded at $760 \mathrm{~nm}$. In this work gallic acid was used as a reference at various concentrations and recorded at 
the same wavelength. The result of calibration curve follows the linear regression equation of $y=0.004 x$ - $0.032\left(R^{2}=0,985\right)$. The total phenolic content is, therefore, expressed as mg Gallic Acid Equivalents (GAE) per $g$ of plant extract.

Total flavonoid content was obtained by using rutin as standard reference at various concentrations ${ }^{17}$. The absorbance of each sample was recorded at its maximum wavelength, which was obtained at $415 \mathrm{~nm}$. The calibration curve follows the linear regression equation of $y=0.003 x$ $+0.099\left(R^{2}=0.963\right)$. The total flavonoids content is, therefore, expressed as mg Rutin Equivalents (RE) per $g$ of plant extract ${ }^{17}$. The total phenolic and flavonoids content of the extract and each fraction were collected in Table 2.

Antioxidant capacity was expressed as $\mathrm{IC}_{50}(\mu \mathrm{g} / \mathrm{ml})$ of DPPH scavenging activity ${ }^{18}$. The concentrations of each sample used in the antioxidant activity test were 25.00, 12.50, 6.25, and $3.125 \mu \mathrm{g} / \mathrm{mL}$, except for ascorbic acid in various concentrations of $10.00,5.00,2.50,1.25$, and 0.625 $\mu \mathrm{g} / \mathrm{mL}$. From the absorbance of each sample, a linear regression for the corresponding $\mathrm{IC}_{50}$ equations was made to calculate (concentration samples having 50\% inhibitory activity). The inhibition activity $\left(\mathrm{IC}_{50}\right)$ of each sample, and the result is presented in Table 2.

Table 2. Quantitative of total phenolic and flavonoids content, and antioxidant activity of the crude ethanol extract and each fraction from stem of $D$. falcata

\begin{tabular}{lccc}
\hline Sample & $\begin{array}{c}\text { Total phenolic content } \\
(\mathrm{TPC})(\mathrm{mg} \mathrm{GAE} / \mathrm{g})\end{array}$ & $\begin{array}{c}\text { Total flavanoids content } \\
(\mathrm{TFC})(\mathrm{mg} \text { RE/g) }\end{array}$ & $\begin{array}{c}\text { Antioxidant activity } \\
\text { by DPPH method } \\
\left(\mathrm{IC}_{50} \mu \mathrm{g} / \mathrm{ml}\right)\end{array}$ \\
\hline Crude ethanol extract & $1290.8 \pm 7.63$ & $195.6 \pm 1.3$ & $11.02 \pm 0.12$ \\
$\mathrm{n}$-hexane fraction & 0 & 0 & $65.96 \pm 1.22$ \\
Chloroform fraction & $954.2 \pm 5.13$ & $315.6 \pm 1.6$ & $20.33 \pm 0.32$ \\
Ethyl acetate fraction & $2079.2 \pm 5.10$ & $980.0 \pm 1.7$ & $7.56 \pm 0.41$ \\
Residu fraction of ethanol extract & $261.7 \pm 3.37$ & 0 & $27.54 \pm 0.62$ \\
Ascorbic acid (Positive control) & - & - & $1.14 \pm 0.11$ \\
\hline
\end{tabular}

*Data are mean \pm SD for triplicate measurement

Screening of antimicrobial activity of crude ethanol extract and the fraction of stem bark from $D$. falcata was done by using agar disk-diffusion method activities againts pathogenic bacteria i.e. Escherichia coli ATCC 11229, Staphylococcus aureus ATCC25923, Staphylococcus epidermidis FNCC 0048, and Streptococcus mutans through the disk-diffusion method ${ }^{19}$. The zones of inhibitions of each compound against pathogenic bacteria are presented at Table 3.

From this study it could be shown the suitability between qualitative and quantitative data. The total ethanol extract still contains a mixture of both non-polar and relatively polar compounds. After successive fractionation using n-hexane, chloroform, and ethyl acetate solvents, groups of soluble compounds according to the polarity of each solvent should result. n-Hexane should dissolve the relatively non-polar compounds, chloroform should dissolve the relatively semipolar compounds, while ethyl acetate should dissolve the relatively polar compounds. The results of this study showed that between the crude extract and the fractions, the ethyl acetate fraction showed the highest total phenolic content $(2079.2 \pm 5.10 \mathrm{mg} \mathrm{GAE} / \mathrm{g})$ followed by crude ethanol extract (1290.8 $\pm 7.63 \mathrm{mg} \mathrm{GAE} / \mathrm{g})$, chloroform fraction (954.2 $\pm 5.13 \mathrm{mg} \mathrm{GAE} / \mathrm{g}$ ) and then residual fraction of ethanol extract $(261.7 \pm$ $3.37 \mathrm{mg} \mathrm{GAE} / \mathrm{g}$ ).

The total flavonoid contents of crude ethanol extract and this fractions determined by spectrophotometry method were reported as rutine equivalents (RE). Flavonoid content was observed on crude ethanol extract (195.6 $\pm 1.3 \mathrm{mg} \mathrm{RE} / \mathrm{g}$ ), 
chloroform fraction (315.6 $\pm 1.6 \mathrm{mg} \mathrm{RE} / \mathrm{g}$ ), and ethyl acetate $(980.0 \pm 1.7 \mathrm{mg} \mathrm{RE} / \mathrm{g})$. In general, phenolic compounds and including flavonoids can dissolve in chloroform, ethyl acetate, and ethanol, but in different concentrations depending on their structure and polarity. The more polar phenolic compounds are more easily dissolved in more polar solvents. Phenolic compounds generally exhibit antioxidant activity, therefore the antioxidant activity of chloroform and ethyl acetate fractions with $\mathrm{IC}_{50}$ shows very active, although relatively less active than ascorbic acid (positive control). Table 2 shows that the total phenolic and flavonoid content in the ethyl acetate fraction stem of $D$. falcata plant is much higher than that in the chloroform fraction, thus indicating the highest antioxidant activity compared to the other fractions. Several studies have shown that many plants contain phenolic compounds. Flavonoids, are one of the natural phenolic compounds found in fruits, vegetables, grains, barks, roots, stems, flowers, tea and wine ${ }^{20}$. The phenolic compound includes a number of compounds generally having an aromatic ring with one or more hydroxyl groups ${ }^{21}$. The antioxidant potential is usually associated with the content of phenolic compounds due to the conjugated $\pi$-electron system which facilitates electron donation from hydroxyl groups to oxidizing radicals. The antioxidant activity test by DPPH method is based on a radical capture reaction by an antioxidant compound with an oxygen atom transfer mechanism, which will produce stable $\mathrm{DPPH}-\mathrm{H}$ molecules in a non-radical form ${ }^{22}$. The $\mathrm{IC}_{50}$ of each extract and fraction stems of $D$. falcata in this study indicate the presence of phenolic compounds which have very high antioxidant activity. The activity is caused by the content of polyphenol compounds such as flavonoids, tannins, from each extract and the fraction stem of the $D$. falcata. Previous research evaluating the antioxidant activity of methanol extract from the stems of the $D$. falcata parasite on mangoes, Mangifera indica (Anacardiaceae) showed the presence of compounds that have significant antioxidant activity ${ }^{23}$. Several studies have shown the presence of phenolic compounds in the Loranthaceae family, including the leaves of Loranthus micranthus Linn showed
3-O- (3,4,5-trimethoxybenzoyl)-(-) -epicatechin (TMECG), (-)-epicatechin-3-O-(3"-O-methyl)-gallate $\left(\mathrm{ECG}_{3} " \mathrm{Me}\right)$, rutine, and peltatoside ${ }^{24}$. Whereas in Scurrula ferruginea Durrer (Loranthaceae) found phenol compounds, quercetin and quercitrin, and 4-O-acetylquercitrin flavonol glycosides ${ }^{25}$. These phenolic compounds show high antioxidant activity.

Table 3 shows that the activity of crude ethanol extract from stem of $D$. falcata has a larger zone diameter than the negative control (DMSO $10 \%)$, but much smaller than the positive control (chloramphenicol). This indicates that the extract and its fractions exhibit activity as antimicrobial agent, although not as good as chloramphenicol. The classification of zone inhibition response of bacterial growth based on clear zone diameter includes weak response $(5 \mathrm{~mm})$, medium response (5-10 $\mathrm{mm})$, strong response $(10-20 \mathrm{~mm})$, and very strong response (diameter $20 \mathrm{~mm})^{26}$. Several previous studies have also shown that some methanol extracts of loranthus sp plants have significant antimicrobial activity against different Gram-positive and Gram-negative bacterial, and fungi being tested ${ }^{27}$. The mechanism of antibacterial action may be through various means, including inhibition of cell wall synthesis, inhibition of cell wall permeability, inhibition of cell wall proteins, inhibition of nucleic acid synthesis, and inhibition of microbial metabolisme ${ }^{28}$. The maximum zone of inhibition was $10.46 \pm 3.63 \mathrm{~mm}$ at the maximum concentration used $1 \%$ of crude ethanol extract stems of $D$. falcata against Staphylococcus epidermidis FNCC 0048.

Plant phenolic compounds are main contributors of antioxidant activity and are also responsible for anti-inflammatory, antiviral and anticancer and antimicrobial activities ${ }^{29}$. The presence of terpenoids and saponin have already shown as antimicrobial and antiinflammatory activity ${ }^{30}$. The results of this study show that the stem bark of $D$. falcata plant contains a high number of phenolic compounds, has antioxidant activity, and exhibits moderate antimicrobial activity. Isolation and identification of the compound structure of the $D$. falcata plant is being analyzed in our laboratory. 
Table 3: Zones of inhibitions as shown by crude ethanol extract and its fraction of stem bark from D. falcata at different concentrations against selected microorganisms

\begin{tabular}{|c|c|c|c|c|c|c|}
\hline \multirow[t]{2}{*}{ No } & \multirow[t]{2}{*}{ Sampel } & \multirow[t]{2}{*}{$\begin{array}{l}\text { Poncentration } \\
\qquad(\%)\end{array}$} & \multicolumn{4}{|c|}{$\begin{array}{l}\text { Diameter Zona of Inhibition (Mean } \pm \text { SD)mm after } 12 \mathrm{~h} \\
\text { incubations }\end{array}$} \\
\hline & & & $\begin{array}{l}\text { Streptococcus } \\
\text { mutans }\end{array}$ & $\begin{array}{c}\text { Staphylococcus } \\
\text { epidermidis } \\
\text { FNCC } 0048\end{array}$ & $\begin{array}{c}\text { Staphylococcus } \\
\text { aureus } \\
\text { ATCC25923 }\end{array}$ & $\begin{array}{c}\text { Escherichia } \\
\text { coli } \\
\text { ATCC } 11229\end{array}$ \\
\hline 1 & DMSO (10\%) & & $6.17 \pm 0.14$ & $6.17 \pm 0.22$ & $6.57 \pm 0.80$ & $6.17 \pm 0.84$ \\
\hline \multirow[t]{4}{*}{2} & Crude ethanol & 0.01 & $10.36 \pm 0.13$ & $10.12 \pm 0.87$ & $8.00 \pm 0.53$ & $8.92 \pm 0.71$ \\
\hline & extract of $D$. falcata & 0.1 & $9.67 \pm 0.53$ & $10.12 \pm 0.87$ & $8.45 \pm 0.05$ & $9.18 \pm 0.03$ \\
\hline & & 0.5 & $9.68 \pm 0.82$ & $10.06 \pm 0.87$ & $8.28 \pm 0.68$ & $9.23 \pm 0.58$ \\
\hline & & 1 & $7.75 \pm 0.29$ & $10.46 \pm 0.63$ & $8.06 \pm 0.59$ & $8.72 \pm 0.22$ \\
\hline \multirow[t]{4}{*}{3} & n-Hexane & 0.01 & $9.37 \pm 0.50$ & $9.14 \pm 0.19$ & $8.77 \pm 0.07$ & $7.48 \pm 0.39$ \\
\hline & fraction of $D$. falcata & 0.1 & $9.41 \pm 0.53$ & $8.46 \pm 0.16$ & $8.03 \pm 0.31$ & $8.33 \pm 0.33$ \\
\hline & & 0.5 & $9.54 \pm 0.51$ & $7.97 \pm 0.62$ & $8.12 \pm 0.74$ & $8.64 \pm 0.87$ \\
\hline & & 1 & $8.59 \pm 0.85$ & $8.14 \pm 0.56$ & $8.31 \pm 0.51$ & $8.35 \pm 0.33$ \\
\hline \multirow[t]{4}{*}{4} & Chloroform & 0.01 & $9.14 \pm 0.30$ & $9.23 \pm 0.68$ & $8.13 \pm 0.28$ & $8.12 \pm 0.85$ \\
\hline & fraction of $D$. falcata & 0.1 & $9.83 \pm 0.61$ & $9.02 \pm 0.98$ & $7.32 \pm 0.82$ & $8.33 \pm 0.33$ \\
\hline & & 0.5 & $10.49 \pm 0.32$ & $8.82 \pm 0.18$ & $9.59 \pm 0.29$ & $8.67 \pm 0.48$ \\
\hline & & 1 & $8.54 \pm 0.39$ & $8.36 \pm 0.77$ & $10.09 \pm 0.36$ & $8.44 \pm 0.37$ \\
\hline \multirow[t]{4}{*}{5} & Ethyl acetate & 0.01 & $9.83 \pm 0.41$ & $7.95 \pm 0.48$ & $7.95 \pm 0.48$ & $8.84 \pm 0.63$ \\
\hline & fraction of $D$. falcata & 0.1 & $8.90 \pm 0.42$ & $7.43 \pm 0.43$ & $7.43 \pm 0.43$ & $8.09 \pm 0.08$ \\
\hline & & 0.5 & $8.67 \pm 0.50$ & $7.20 \pm 0.53$ & $7.20 \pm 0.53$ & $8.33 \pm 0.47$ \\
\hline & & 1 & $7.75 \pm 0.29$ & $7.54 \pm 0.35$ & $7.54 \pm 0.35$ & $8.09 \pm 0.49$ \\
\hline \multirow[t]{4}{*}{6} & Residual of ethanolic & 0.01 & $10.36 \pm 0.13$ & $8.73 \pm 0.38$ & $7.44 \pm 0.29$ & $8.41 \pm 0.40$ \\
\hline & fraction of $D$. falcata & 0.1 & $9.67 \pm 0.53$ & $8.12 \pm 0.65$ & $7.81 \pm 0.43$ & $8.77 \pm 0.47$ \\
\hline & & 0.5 & $9.68 \pm 0.82$ & $8.98 \pm 0.06$ & $6.98 \pm 0.50$ & $7.92 \pm 0.54$ \\
\hline & & 1 & $7.75 \pm 0.29$ & $8.15 \pm 1.13$ & $7.28 \pm 0.52$ & $7.95 \pm 1.02$ \\
\hline \multirow[t]{4}{*}{7} & Chloramphenicol & 0.01 & $12.26 \pm 0.72$ & $12.57 \pm 1.88$ & $12.37 \pm 1.38$ & $17.41 \pm 1.88$ \\
\hline & (positive controle) & 0.1 & $17.05 \pm 0.93$ & $20.58 \pm 1.09$ & $11.25 \pm 1.67$ & $22.38 \pm 1.11$ \\
\hline & & 0.5 & $21.20 \pm 0.41$ & $24.05 \pm 1.52$ & $13.70 \pm 2.90$ & $28.26 \pm 1.68$ \\
\hline & & 1 & $22.52 \pm 0.72$ & $24.98 \pm 1.06$ & $17.35 \pm 1.07$ & $32.57 \pm 1.88$ \\
\hline
\end{tabular}

\section{CONCLUSION}

The study showed the presence of total phenolic content and flavonoids from extracts and fractions from stems of $D$. falcata. Ethyl acetate fraction from stems of $D$. falcata showed the highest phenolic and flavonoid levels, as well as very high antioxidant activity. Zones of inhibition of extracts and each fraction showed moderate activity against Escherichia coli ATCC 11229, Staphylococcus aureus ATCC25923, Staphylococcus epidermidis FNCC 0048, and Streptococcus mutans. This study shows that stems of $D$. falcata contain potential phenolic compounds that can be suitable as natural antioxidants and treatment of various infections caused by microbes.

\section{ACKNOWLEDGEMENT}

This work was supported by the Ministry of Research and Technology of the Directorate of Higher Education, Indonesia for funding of competency research grants (PBK, Number: 0045 / E3/ LL/ 2018, January 16, 2018) and foreign seminar aid program (BSLN, MENRISTEK DIKTI) Indonesia has provided financial assistance to attend the ISTEC 2018 international seminar. The author also thanks to Prof.K. H. Sugiyarto from Department Chemistry Ed. Yogyakarta State University which helps review the manuscript.

\section{REFERENCES}

1. Moghadamtousi SZ, Noor M, Kamarudin A, Chan CK, Goh BH, Kadir HA. The American
Journal of Chinese Medicine., 2014, 42 (1):23-35. 
2. Chandrakasan L, Neelamegan R, . Journal of Pharmacy Research., 2011, 4(9), 3072-74.

3. Krishnaveni $R$, Valliappan $R$, Selvaraju $P$, Nagendra Prasad. Journal of Pharmacognosy and Phytochemistry., 2016, 5(6), 07-11.

4. Ogunmefun OT, Fasola TR, Saba AB, Oridupa OA. Int J Biomed Sci., 2013, 9(1), 33-40.

5. Wong DZH, Kadir HA, Lee CL, Goh BH. J. Ethnopharmacol., 2012, 139, 256-264.

6. Govindappa M, Channabasava R, Sowmya DV, Meenakshi J, Shreevidya MR,Lavanya A, Gustavo Santoyo and Sadananda TS. Pharmacognosy Journal., 2011, 3(25), 82-90.

7. Wong, D.Z.H., H.A. Kadir, C.L. Lee and B.H. Goh. J. Nat. Med., 2012, 66, 544-551.

8. Chandrakasan L, Neelamegam R. Plant Archives., 2012, 12(1):31-40.

9. Ukpanukpong RU, Adekunle IA, Uyabeme RN, Adeleke CO. Journal of Advances in Medical and Pharmaceutical Sciences., 2017, 13(1), 1-12.

10. Pattanayak SP, Mazumder PM. Phcog Mag., 2009, 5, 98-105.

11. Patil S, Anarthe $S$, Jadhav R, Surana S. Iran J Pharm Res., 2011, 10 (2), 253-9.

12. Osadebe PO, Ukwueze SE. Bio-Research., 2004, 2(1), 18-23.

13. Chandrakasan L. and Neelamegam R. Journal of Medicinal Plants Studies., 2017, 5(1), 135-9.

14. Rajdoula Md. R., Ahsan M., Hasan C.H., Masud M.M., J. Pharm. Sci., 2017, 16(2), 215-219.

15. Harborne AJ. Phytochemical Methods a Guide to Modern Techniques of Plant Analysis. $3^{\text {rd }}$ ed. Springer Netherlands., 1998.

16. Hagerman A, Harvey-Mueller I, Makkar A.H, Mueller IH, Makar H.P.S. Quantification of
Tannins in Tree Foliage-aLaboratory Manual; FAO/IAEA: Vienna., 2000.

17. Liu C.T, Wu Ching-Yi, WengYih-Ming, Tseng Chin-Yin. J. Ethnopharmacol., 2005, 99, 293-300.

18. Hanumantharaju N, Shashidhara S, Rajasekharan P.E, Rajendra C.E. Inter $J$ of Pharmacy and Pharmaceutical Sciences., 2010, 2(4), 72-5.

19. Bishnu PM, Pankaj B, Pratibha A, Kashi RG, Sanjiv N, Nabara D. BioMed Res Int., 2015, 2015, 1-6.

20. Panche A.N., Diwan A.D., Chandra S.R., Journal of Nutritional Science., 2016, 5(47), 1-15.

21. Bors W, Michel C. Ann NY Acad Sci., 2002, 957, 57-69.

22. Molyneux P., Songklanakarin. J.Sci. Technol., 2004, 26(2), 211-219.

23. Anarthe S.J., Bhalke R.D., Jadhav R.B., Surana S. J., Biomed., 2008, 3(2), 182-189.

24. Agbo M.O., Nworu C.S., Okoye F.B.C., Osadebe P.O. EXCLI Journal., 2014, 13, 859-868.

25. Devehat F. L., Tomasi S, Fontanel D, Boustie J., Z Naturforsch C., 2002, 57 (11-12), 1092-5.

26. Davis, W. W. And Stout T. R. American Society for Microbiology., 1971, 4 (22), 659-665.

27. Govindappa M, Channabasava R, Sowmya DV, Meenakshi J, Shreevidya MR, Lavanya A, Gustavo S, and Sadananda TS. Pharmacog. J., 2011, 3(25), 82-90.

28. Jawetz, Melnick, dan Adelberg. 2008. Medical Microbiology. Jakarta: Salemba Medika., 2008.

29. Yang C, Chang H, Lin H, Chuang L. J.Pharmacogn. Phytochem., 2013, 2(1), 294-305.

30. Mandal P, Babu SSP, Mandal NC. Fitoterapia., 2005, 76(5), 462-465. 